\title{
UMA INVESTIGAÇÃO QUALITATIVA SOBRE O MÉTODO PBL UTILIZADO NO CURSO DE ENGENHARIA DE COMPUTAÇÃO
}

\author{
Carlos Alberto dos Santos da Silva ${ }^{1}$; David Moises Barreto dos Santos ${ }^{2}$ \\ 1. Bolsista PROBIC/UEFS, Graduando em Engenharia de Computação, Universidade Estadual de Feira de Santana, e-mail: \\ carlosadsds@gmail.com \\ 2. Orientador, Departamento de Ciências Exatas, Universidade Estadual de Feira de Santana, \\ e-mail: davidmbs@uefs.br
}

PALAVRAS-CHAVE: PBL, Avaliação, Engenharia de Computação.

\section{INTRODUÇÃO}

O método PBL (Problem-Based Learning) usado no curso de Engenharia de Computação da UEFS, tem como finalidade fazer do aluno o principal ator do seu processo de aprendizagem, enquanto o professor assume a responsabilidade de acompanhar tal processo. Além disso, também objetiva aliar a teoria com a prática. Motivados por um problema que simula situações do mundo real, os alunos se reúnem em pequenos grupos para debatê-lo, além de propor e implementar uma solução para o problema dado (Duch, Groh, \& Allen, 2001; Santos, Pinto, Sena, Bertoni, \& Bittencourt, 2007).

Apesar de o curso funcionar desde 2003 e muitos aspectos do PBL já terem sido lapidados, ainda existe uma carência de uma avaliação geral do método. As avaliações ocorridas até então se deram apenas por publicações científicas que abordaram disciplinas específicas e relato de experiência a partir da percepção docente (M. Angelo \& Bertoni, 2011; M. F. Angelo, Loula, \& Bertoni, 2014; Santos, Pinto, et al., 2007; Santos, Saba, Junior, \& Sarinho, 2007).

Neste sentido, tomamos a seguinte questão de pesquisa como norte para avaliar o método: qual a percepção que o graduando de Eng. de Computação tem acerca do PBL?

Uma vez que deverá estar atuando em consonância com a Comissão de Avaliação PBL do curso de Engenharia de Computação, os resultados da presente pesquisa contribuirão significativamente para o referido curso no sentido de ter acesso as opiniões dos educandos, podendo manter o que é positivo e mudar aquilo que ainda pode ser melhorado.

\section{MATERIAL E MÉTODOS}

A população participante deste estudo foi de 19 sujeitos, que representavam uma amostra aleatória de $8 \%$ dos estudantes matriculados em Módulos Integradores (MI) no semestre 2015.1, no curso de Engenharia de Computação. O MI é um componente curricular que representa uma aliança multidisciplinar entre diferentes disciplinas e entre prática e teoria. Dos entrevistados, $89,5 \%$ eram do sexo masculino, enquanto $10,5 \%$ eram do sexo feminino. A média de idade da população entrevistada foi de 21 anos (desvio padrão $=2,95$ ).

Para coletar os dados deste estudo, utilizamos uma entrevista semiestruturada composta por questões que visavam extrair uma síntese sobre a experiência dos estudantes do curso com o PBL. Adotamos essa estratégia na tentativa de garantir maior flexibilidade tanto para o entrevistador, quanto para o entrevistado.

Podemos citar como procedimentos, que a extração da amostra foi feita através do software SPSS; o convite para que os estudantes participassem da entrevista foi realizado pessoalmente ou por e-mail; as entrevistas aconteceram entre dezembro de 2015 e março de 2016, sendo conduzidas por dois pesquisadores envolvidos no projeto. As entrevistas somaram 10 horas e 20 minutos, com uma média de aproximadamente 33 minutos para cada uma. A presente pesquisa foi aprovada pelo Comitê de Ética em Pesquisa. Todos os entrevistados consentiram a gravação das entrevistas e assinaram o termo de consentimento livre e esclarecido. 
Por fim, o processo de análise das entrevistas foi feito através da análise de conteúdo (Bardin, 1977), com o auxílio do software NVIVO 10. Após serem transcritas, as entrevistas foram codificadas através de categorias pré-definidas de acordo com os temas abordados na entrevista. Na medida em que a codificação avançava, as categorias eram revisadas de modo a contemplar melhor o que foi coletado durante a entrevista.

\section{RESULTADOS E DISCUSSÃO}

Após serem analisadas e codificadas, as entrevistas foram divididas em cinco categorias principais: avaliação do método PBL, problema, adaptação ao método PBL, grupo tutorial, e, por fim, tutor e feedback. Visando explorar essas categorias objetivamente, criamos uma tabela composta por quatro campos: tema, item, ideias repetidas e frequência.

No campo "Tema" estão expostas as cinco categorias geradas a partir da codificação das entrevistas:

- Avaliação do método PBL: verificou o nível de aprovação do método pelos estudantes, bem como o que eles mais gostavam e menos gostavam no PBL, além das habilidades que desenvolveram durante a experiência com essa abordagem de ensino-aprendizagem.

- Problema: Em seguida, abordamos os problemas trabalhados nas sessões tutoriais, visando entender se os entrevistados aprovavam, se eram motivadores e se os prazos para desenvolver uma solução eram adequados.

- Adaptação: Também procuramos entender se os estudantes se sentiam adaptados ao método PBL e quais os fatores que facilitavam ou dificultavam essa adaptação.

- Grupo Tutorial: Para tratar dos grupos tutoriais, investigamos: como era a dinâmica entre os estudantes dentro e fora das sessões tutoriais; se haviam problemas de relacionamento nos grupos (e o que motivava isso); qual deveria ser a quantidade ideal de estudantes em um grupo para que as sessões fossem producentes; e se os estudantes conheciam e seguiam o ciclo PBL durante as discussões.

- Tutor e Feedback: Por fim, a última categoria foi responsável por abordar os itens sobre tutor e feedback, afim de entender: com que frequência os professores forneciam feedbacks para o grupo nas sessões tutoriais; de que forma acontecia o feedback dos produtos desenvolvidos pelos estudantes; se os tutores forneciam feedbacks sobre o desempenho individual de cada estudante; se os tutores deixavam claros os critérios para avaliar os estudantes e se esses critérios eram coerentes com a avaliação; e, por fim, se os entrevistados faziam críticas aos tutores e como estes reagiam.

No campo "Item" foram colocados os principais itens referentes a cada tema codificado, como uma espécie de subcategoria.

No campo "Ideias Repetidas" estão os pontos de vista mais citados pelos estudantes durante as entrevistas.

O campo "Frequência Relativa" é o último da tabela e se refere a quantidade de vezes que uma determinada ideia se repetiu no discurso dos 19 estudantes entrevistados. Ou seja, é a porcentagem obtida através da divisão entre a frequência absoluta (número de estudantes que falou sobre a mesma ideia) e a quantidade de sujeitos da população entrevistada.

A Tabela 1 resume os resultados obtidos através da codificação das entrevistas, exibindo os cinco temas principais, os itens abordados em cada tema, as ideias que mais citadas pelos estudantes e a frequência relativa de cada uma delas. 
Tabela 1. Resultados obtidos a partir da análise e codificação das entrevistas.

\begin{tabular}{|c|c|c|c|}
\hline TEMA & ITEM & IDEIAS REPETIDAS & $\begin{array}{l}\text { FREQUÊNCIA } \\
\text { RELATIVA (\%) }\end{array}$ \\
\hline \multirow{14}{*}{$\begin{array}{c}\text { AVALIAÇÃO } \\
\text { DO MÉTODO } \\
\text { PBL }\end{array}$} & \multirow{2}{*}{ Aprovação } & Aprovo o PBL & 78,9 \\
\hline & & Aprovo o PBL, com restrições & 21,1 \\
\hline & \multirow{5}{*}{ O que mais gosta } & Aprendizagem ativa & 63,1 \\
\hline & & AplicaçãodoPBLcomomodelo de estudo para outras disciplinas & 15,8 \\
\hline & & Trabalho em grupo & 63,1 \\
\hline & & Articulação entre disciplinas PBL e disciplinas tradicionais & 42,1 \\
\hline & & Postura adequada do tutor em sessão & 21,0 \\
\hline & \multirow{4}{*}{ O que menos gosta } & Prazos Apertados & 26,3 \\
\hline & & Trabalho em grupo & 26,3 \\
\hline & & Articulação entre disciplinas PBL e disciplinas tradicionais & 21,0 \\
\hline & & Postura inadequada do tutor em sessão & 26,3 \\
\hline & \multirow{3}{*}{$\begin{array}{l}\text { Habilidades } \\
\text { Desenvolvidas }\end{array}$} & Aprendizado autodirigido & 36,8 \\
\hline & & Comunicação & 31,5 \\
\hline & & Organização & 31,5 \\
\hline \multirow{7}{*}{ PROBLEMA } & \multirow{2}{*}{ Aprovação } & Aprovo os problemas aplicados no curso & 84,2 \\
\hline & & Desaprovo os problemas aplicados no curso & 15,8 \\
\hline & \multirow{2}{*}{ Motivador } & Os problemas motivam meu aprendizado & 89,5 \\
\hline & & Os problemas não motivam meu aprendizado & 5,26 \\
\hline & \multirow{3}{*}{ Prazo adequado } & Prazo para entregar a solução é adequado & 63,1 \\
\hline & & Prazo para entregar a solução depende do problema & 26,3 \\
\hline & & Prazo para entregar a solução não é adequado & 10,5 \\
\hline \multirow{9}{*}{ ADAPTAÇÃO } & \multirow{2}{*}{$\begin{array}{c}\text { Situação atual do } \\
\text { estudante }\end{array}$} & Me sinto adaptado ao PBL & 78,9 \\
\hline & & Não me sinto adaptado ao PBL & 21,1 \\
\hline & \multirow{4}{*}{$\begin{array}{c}\text { Fatores que } \\
\text { favorecem a } \\
\text { adaptação ao PBL }\end{array}$} & Oficina PBL & 21,0 \\
\hline & & Habilidades Pessoais & 21,0 \\
\hline & & Postura do tutor & 10,5 \\
\hline & & Aprendizado contínuo & 15,8 \\
\hline & \multirow{3}{*}{$\begin{array}{l}\text { Fatores que dificultam } \\
\text { a adaptação ao PBL }\end{array}$} & Mudança de método de ensino-aprendizagem & 68,4 \\
\hline & & Conteúdo programático novo & 26,3 \\
\hline & & Atividades paralelas à universidade & 15,8 \\
\hline \multirow{14}{*}{$\begin{array}{c}\text { GRUPO } \\
\text { TUTORIAL }\end{array}$} & \multirow{3}{*}{ Dinâmica do grupo } & Colegas contribuem p/ o bom andamento da sessão & 42,1 \\
\hline & & Depende do grupo tutorial & 31,8 \\
\hline & & Apresenta problemas & 10,5 \\
\hline & \multirow{3}{*}{$\begin{array}{l}\text { Colaboração fora da } \\
\text { sessão }\end{array}$} & Ocorre frequentemente & 57,9 \\
\hline & & Ocorre esporadicamente & 26,3 \\
\hline & & Não ocorre & 5,3 \\
\hline & \multirow{3}{*}{$\begin{array}{l}\text { Causas dos problemas } \\
\text { de relacionamento }\end{array}$} & Discordância de ideias & 42,1 \\
\hline & & Equidade nas falas & 21,1 \\
\hline & & Falta de comprometimento & 21,1 \\
\hline & \multirow{3}{*}{$\begin{array}{l}\text { Quantidade de } \\
\text { membros }\end{array}$} & O número ideal é entre 6 a 7 membros & 36,8 \\
\hline & & O número ideal é entre 8 e 10 membros & 57,9 \\
\hline & & Mais que 10 membros é ruim & 36,8 \\
\hline & \multirow{2}{*}{ Ciclo PBL } & Os estudantes sabem o que é & 35,3 \\
\hline & & Os estudantes não sabem o que é & 64,7 \\
\hline \multirow{8}{*}{$\begin{array}{c}\text { TUTOR E } \\
\text { FEEDBACK }\end{array}$} & \multirow{3}{*}{$\begin{array}{c}\text { Feedback nas sessões } \\
\text { tutoriais }\end{array}$} & Fornecido em toda sessão & 57,9 \\
\hline & & Não era fornecido & 57,9 \\
\hline & & Fornecido esporadicamente & 36,8 \\
\hline & Feedback dos & Ocorria de maneira quantitativa & 57,9 \\
\hline & produtos & Ocorria de maneira qualitativa & 68,4 \\
\hline & Feedback do & Não era fornecido & 31,6 \\
\hline & desempenho & Era fornecido esporadicamente & 15,8 \\
\hline & individual & Era fornecido no fim da sessão & 15,8 \\
\hline
\end{tabular}




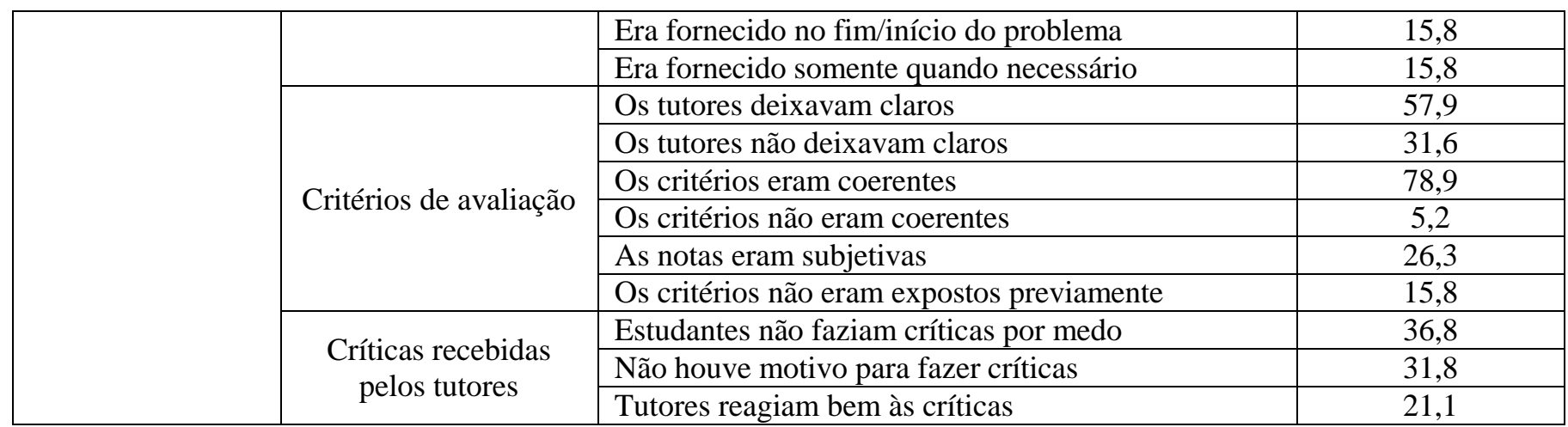

\section{CONSIDERAÇÕES FINAIS}

Após a análise das entrevistas, pôde-se concluir que os estudantes do curso de Engenharia de Computação da UEFS aprovaram o método PBL, ainda que alguns tivessem algumas ressalvas quanto a sua aplicação; os problemas receberam um saldo de comentários positivos; a maioria dos entrevistados se sente adaptada ao PBL, conseguindo desenvolver habilidades específicas por causa do método; o grupo tutorial é uma ferramenta tão fundamental para o aprendizado individual e coletivo, que adequar o número de membros em uma sessão tutorial contribui diretamente na colaboração de todos os indivíduos em sessão (ou fora dela), constituindo fatores importantes para o sucesso da solução de um problema; os tutores possuem um papel importante nas sessões tutoriais e fornecer feedbacks de sessão, dos produtos e dos estudantes faz parte disso, mas os entrevistados perceberam que apesar de alguns professores divulgarem avaliações qualitativas, ainda existe um longo caminho para que esse retorno seja executado corretamente, de maneira a abranger, por exemplo, os critérios de avaliação (que na maioria das vezes não são expostos).

As limitações desse trabalho abrangeram o fato de que as entrevistas focaram em momentos específicos da experiência dos educandos. Nesse sentido, como possível sugestão de trabalho futuro está a investigação da percepção discente em relação ao método PBL, ao longo do tempo. Também é relevante avaliar a percepção dos tutores.

\section{REFERÊNCIAS}

ANGELO, M. F.; BERTONI, F. C. Análise da aplicação do método PBL no processo de ensino e aprendizagem em um curso de Engenharia de Computação. Revista do Ensino de Engenharia, v.30. n. 2, pg. 35-42, 2011.

ANGELO, M.F.; LOULA, A.C.; BERTONI, F.C.; SANTOS, J.A.M. Aplicação e Avaliação do Método PBL em Um Componente Curricular Integrado de Programação de Computadores. Revista de Ensino de Engenharia, v. 33, p. 31-43, 2014.

BARDIN, L. Análise de Conteúdo. Trad. de Luís Antero Reto e Augusto Pinheiro. Lisboa. Ed. 70, 1977. DUCH, B.J., GROH, S.E. \& ALLEN, D.E. The Power of Problem-Based Learning: A Practical "How To" for Teaching Undergraduate Courses in Any Discipline, Stylus Pub. 2001.

SANTOS, D.M.B., PINTO G.R.P.R., SENA, C.P.P., BERTONI, F.C., BITTENCOURT, R.A. Aplicação do método de aprendizagem baseada em problemas no curso de Engenharia da Computação da Universidade Estadual de Feira de Santana. In: Congresso Brasileiro de Educação em Engenharia-COBENGE. 2007.

SANTOS, D. M. B.; SABA, H.; JUNIOR, J. R.; SARINHO, V. Aplicando Project- Based Learning no Estudo Integrado de Engenharia de Software, Análise e Projeto de Sistemas e Banco de Dados. In: XXXV Congresso Brasileiro de Educação em Engenharia, Curitiba, Paraná, 2007. 